\title{
MULTIPLE CARBON ACCOUNTING TO SUPPORT JUST AND EFFECTIVE CLIMATE POLICIES
}

Karl W. Steininger ${ }^{1,2}$, Christian Lininger ${ }^{2}$, Lukas H. Meyer ${ }^{3}$, Pablo Muñoz ${ }^{4}$ and Thomas Schinko ${ }^{2,5}$

Final Author Version of:

Steininger, K.W., C. Lininger, L.H. Meyer, P. Munoz, T. Schinko (2015). Multiple carbon accounting to support just and effective climate policies. Nature Climate Change 6, 35-41. (Published online 23 November 2015). doi:10.1038/nclimate2867. Available at:

http://www.nature.com/nclimate/journal/vaop/ncurrent/full/nclimate2867.html

\begin{abstract}
Negotiating greenhouse gas (GHG) emission reduction involves the allocation of emissions and of emission reductions to specific agents, and notably, within the current UN framework, to associated countries. As production takes place in supply chains, increasingly extending over several countries, there are various options available in which emissions originating from one and the same activity may be attributed to different agents along the supply chain and thus to different countries. In this way, several distinct types of national carbon accounts can be constructed. We argue that these accounts will typically differ as regards the information they provide to individual countries on the effects their actions have on global emissions; and they may also, to varying degrees, prove useful in supporting the pursuit of an effective and just climate policy. However, none of the accounting systems proves "best" in achieving these aims under real world circumstances; we thus suggest compiling reliable data to facilitate the consistent calculation of multiple carbon accounts on a global level.
\end{abstract}

\footnotetext{
${ }^{1}$ University of Graz, Department of Economics, Universitaetsstrasse 15, A-8010 Graz, Austria

${ }^{2}$ University of Graz, Wegener Center for Climate and Global Change, Brandhofgasse 5, A-8010 Graz, Austria

${ }^{3}$ University of Graz, Department of Philosophy, Attemsgasse 25/II, A-8010 Graz, Austria

${ }^{4}$ United Nations University, Vice Rectorate in Europe (UNU-ViE), Platz der Vereinten Nationen 1, D-53113 Bonn, Germany

${ }^{5}$ International Institute for Applied Systems Analysis (IIASA), Schlossplatz 1, A-2361 Laxenburg, Austria
} 


\section{Emission accounting principles}

The current UN GHG emission allocation system attributes emissions to that country in which emissions physically occur during production (production-based principle). ${ }^{1}$ Three core alternatives have been proposed in the literature. First, irrespective of where they emerge in the supply chain, emissions could be attributed to the country that extracts the fossil fuels that allow for these emissions (extraction-based principle). ${ }^{2}$ Second, one could acknowledge that factors other than fossil fuels, such as labor and capital, also benefit from a polluting production process by earning income (wages, interest, rents). Thus, all emissions discharged along the supply chain could be attributed to specific agents (and countries) according to the value they add in production - and thus according to the income they earn (income-based principle, enabled emissions, downstream responsibility).,34 Finally, emissions occurring in the production process may also be attributed to the very end of the supply chain, i.e. to the consumer (or more precisely: the final user) and her country of residence (consumption-based principle, upstream responsibility). ${ }^{5,6}$

As shown in Figure 1, the global distribution of per capita GHG emissions varies considerably depending on which of these four principles is employed.

\section{The "responsibility" discussion and the question of justice}

Propositions for using any one of the above accounting systems are often framed in terms of a need to attach "responsibility for emissions" to a particular type of agent (consumer, producer, extractor, or income beneficiary) and consequently to allocate emissions to that agent. $3,4,7,8,9,10,11,12$ This literature can be interpreted to be based on the principle of compensatory justice (i.e. the obligation to compensate for the damage arising ${ }^{3,4,11}$ or the benefits gained ${ }^{7,9}$ from emissions).

We, however, suggest that the question of how one should respond to climate damage is primarily a question of distributive justice and is thus more a matter of redistribution than of compensation. Distributive justice, as understood here, specifies a baseline distribution in accordance with a specific criterion (such as strict equality or sufficiency) and allows for changes of this distribution owing to people's own responsible (and non-wrongful) choices. Deviations from the baseline may be the result of luck, wrongful harm-doing, or wrongless harm-doing. A duty of compensation only arises in cases of wrongful harm-doing. Any responsibilities to pay for climate damages or measures of adaptation that cannot be linked to wrongful harm-doing must be justified by the redistributive rationale..$^{13,14,15}$ 
Figure 1: Global emissions per capita according to different accounting principles (year 2011).
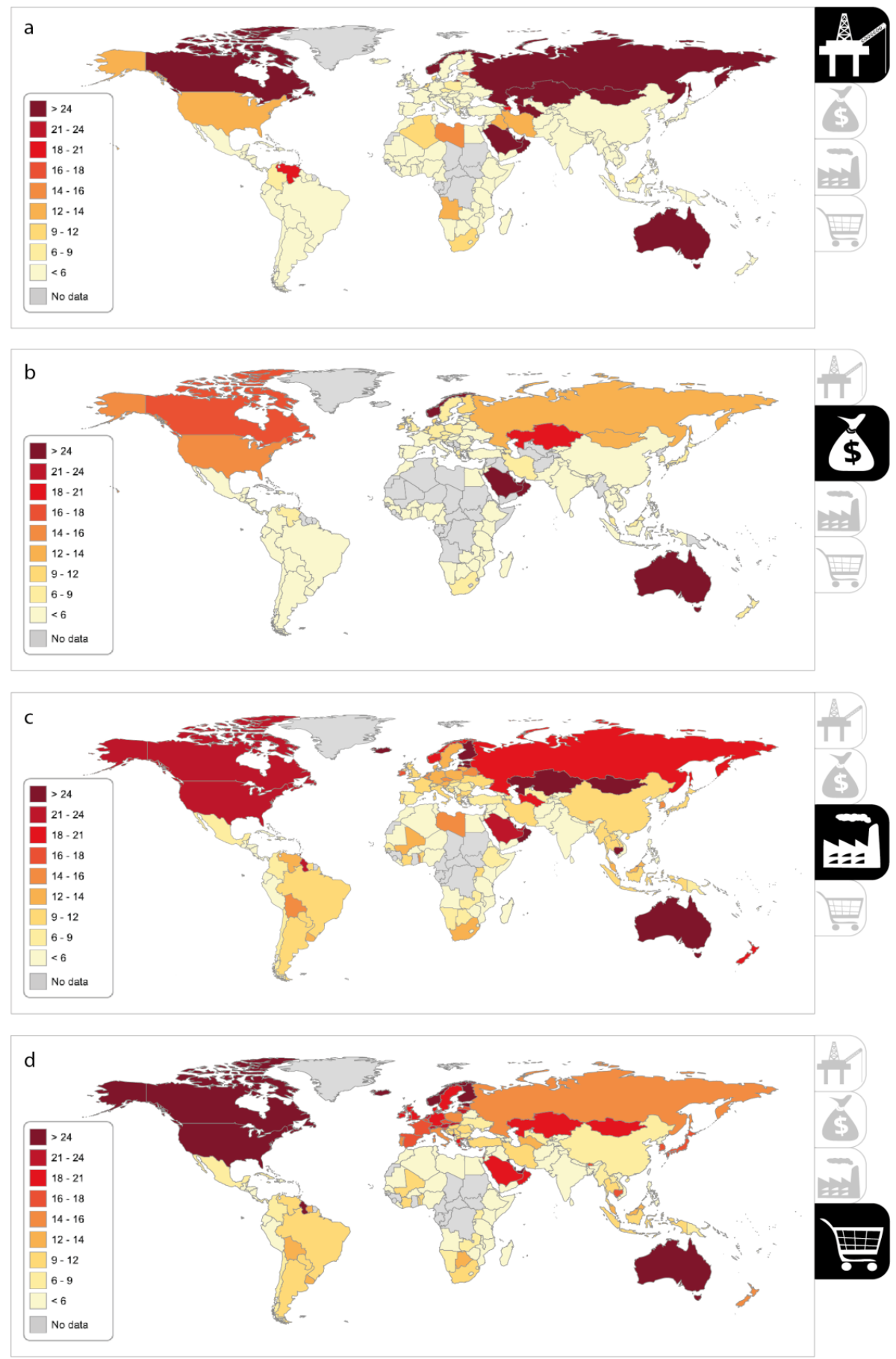

Panels show emissions per capita according to: (a) Extraction-Based Accounting, reflecting the carbon content of fossil fuels extracted; (b) Income-Based Accounting, allocating emissions along the production chain based on the supply of factors of production; (c) Production-Based Accounting, assigning emissions to the country releasing the pollutant; (d) Consumption-Based Accounting, attributing emissions to final users of goods and services produced.

Note: panels (a) and (b) cover only $\mathrm{CO}_{2}$ emissions per from energy use (source: own calculations). Panels (c) and (d) cover all GHG in $\mathrm{tCO}_{2} \mathrm{e}$ (source: EORA ${ }^{98}$ ). See SI for methodological and data information, and additional panels. Design: Wegener Center/Sabine Tschuertz. 
There are three main relevant principles of compensatory justice: $:^{16,17,18,19}$ The Polluter Pays Principle (PPP) attributes the compensation responsibility to the wrongful emitter, the Beneficiary Pays Principle (BPP) to the beneficiary of wrongful emissions, and the Community Pays Principle (CPP) to people based on their membership of a community in which they or some other (previous) members caused the wrongful emissions. ${ }^{20,21,22,23,24}$ In contexts other than climate change, PPP is more widely accepted than either BPP or CPP.

At least four problems arise when determining compensation on the basis of PPP. First, there is the problem of identifying those agents who are causally responsible for the harmful emissions. Applying the "but-for" test is no help. No matter for which agent we perform the test, we find that but for their actions there would have been no emissions..$^{25,26,27,28,29,30}$ Second, there is no agreement on how to determine relative causal shares in any instance of joint causation of harm, where each single agent's contributions were neither necessary nor sufficient. ${ }^{31,32}$ Third, it is difficult to identify those people harmed in the future as a result of actions carried out in the present, when the latter are necessary conditions for the very existence of the allegedly harmed persons, when these persons will have 'a life worth living' (the so-called non-identity problem) ${ }^{33,34}$. Fourth, potential bearers of compensatory duties might be blamelessly ignorant of the harmful impact of their emissiongenerating activities. Even if they can be said to have known about the consequences, their actions may be permissible if restricting their emissions to protect future generations were to place excessive demands on them. . $^{35,36,37,38}$

These problems have the potential to seriously limit the applicability of compensatory justice. Thus, compensation payments for climate damage are very difficult to justify. Insofar as justifications succeed, they do so only for a fraction of those who cause and those who suffer from climate change. This has been shown for all three principles of compensatory justice distinguished above. ${ }^{18}$ For our context, this means that even if the harm caused by emission-generating activities could be determined (the third problem) and the blameworthiness of the agents causing the harm established (the fourth problem), we will not be able to identify single (groups of) agents in the supply chain (the extractor, the income generator, the producer, or the consumer) as the agents solely responsible for emissions (the first problem), and the question of meaningfully apportioning responsibility among the agents remains highly contentious (the second problem).

However, as many effects of climate change can be seen as undeserved harms - often associated with undeserved benefits for others - attempting to equalize climate effect impacts on the basis of a concern for distributive justice seems more promising. Given the limited applicability of compensatory justice, the focus should be directed towards achieving a more equitable distribution of undeserved benefits and harms rather than focusing on compensating wronged persons. ${ }^{39,40,41,36}$ 
Assessing policies in terms of distributive justice, however, is outcome-oriented. We ask whose wellbeing is affected by a specific policy and we usually find that not only those who have to carry out the policy are affected. For example, employing a production-based accounting system, climate policy might take the form of a carbon tax applied to the emissions recorded in production-based emissions accounts. This, however, does not imply that the producer will bear the full tax burden. As analyzed in the tax incidence literature ${ }^{42}$, part or even the entire tax burden will be passed on to consumers and suppliers of factors of production. A similar argument can be made for other types of policy instruments and for the other accounting principles. In general, irrespective of which accounting system is chosen, typically all agents along the supply chain are affected. Thus, to evaluate policy outcomes in terms of distributive justice we have to analyze the effects of abatement policies based on the respective accounting principle, and not simply rely on having selected a particular accounting system. For example, it is sometimes argued that consumption-based accounting is "fairer" than production-based accounting ${ }^{9,10}$ because it attributes a larger share of global emissions to industrialized countries. But if consumption-based policies are adopted to meet these targets, the conclusions drawn with respect to "fairness" may actually be reversed ${ }^{43}$ as some types of such policies have been found to pass on a larger part of the abatement burden to developing and emerging economies. ${ }^{44,45}$

\section{Different uses of GHG accounts and evaluation criteria}

As the concept of "responsibility" is therefore not sufficient as a criterion for selecting a specific accounting principle, we need to employ other criteria. There is a broad consensus that international climate policy should be both just and effective. ${ }^{46}$ The system of GHG accounts adopted should support just and effective policymaking. We use two effectiveness criteria suggested by the IPCC, environmental effectiveness and cost-effectiveness ${ }^{46}$, as well as the carbon leakage criterion (affecting both environmental and cost-effectiveness) for comparing policies based on the different GHG accounting principles. The question of justice is evaluated in an outcome-orientated way - by identifying the international distributional effects of the respective policies.

National GHG accounts are employed nationally and internationally (e.g. in the UNFCCC) for a number of different purposes. First, such accounts serve as a reference scale for internationally agreed abatement targets (they serve as a target base ${ }^{47}$ ). The Kyoto Protocol is a prime example. Secondly, individual countries use national GHG accounts to evaluate how their actions and policies influence GHG emissions (monitoring base). Thirdly, policy instruments could target exactly those emissions that are recorded in GHG accounts (instrument base $e^{47,43}$ ). 
Often, these three uses of carbon accounts go hand-in-hand. For example, under the current system of production-based targets, it is natural for individual countries (interested in a good performance with respect to these targets) to use their production-based GHG accounts also as their prime monitoring base. Furthermore, the most effective policy in meeting production-based targets is one geared exactly to those emissions registered in production-based GHG accounts, i.e. a policy relying on the same accounts as an instrument base. A similar argument can be made for all the GHG accounting principles. ${ }^{43}$

By deciding on a target base, international climate negotiators have some control over the type of climate policy that individual countries choose. This is important for assessing the "effectiveness" and "justice" of the four types of GHG accounting systems. As argued above, it is not the accounting system as such that can be considered "just"; and, equally, "effectiveness" does not depend on the accounting system as such. Rather, one has to analyze the impacts of the policy implied by the respective accounting principle. ${ }^{47}$

The type of climate policy currently almost universally followed qualifies as a production-based policy. Consumption-based policies, while discussed in the literature $48,49,47,43,50$, have so far not been implemented in practice, at least not across their full range. One implementation option of such a policy is the use of full border carbon adjustments (BCA). ${ }^{48}$ There is a rich literature on both the possible effects of $B C A^{51,52,53,54,55,44}$ and on options for their practical implementation. ${ }^{56,57,58,59}$ The exemption of exports from GHG pricing (as implemented within the EU ETS ${ }^{60}$ for carbon intensive and trade-exposed industries) can be seen as an example of a partial BCA application. As regards extraction-based policies - currently being discussed under the rubric of "supply-side" policies several proposals exist concerning the introduction of (tradable) depletion quotas or rights to exploit fossil fuel deposits ${ }^{61}$, or carbon-pricing at the point of extraction ${ }^{2}$.

\section{Insights from the analysis of an idealized setting}

The advantages and disadvantages of the adoption of each of the four accounting principles crucially depend on the economic and institutional implementation environment. To provide a point of reference, we first analyze an idealized setting, considered "first-best" by neoclassical economists. If markets are complete and fully competitive and if climate policy (i) covers all GHG emissions globally, and (ii) imposes (at least implicitly) a globally uniform (shadow) price on each type of GHG (which, if it equals marginal damages, additionally ensures overall efficiency), then environmental and cost-effectiveness are guaranteed irrespective of which accounting system is chosen, i.e. irrespective of where in the supply chain (extractor, producer, income beneficiary, or consumer) the 
targets are set and the instruments are applied. In such a setting markets pass on the incentives fully to all other agents in the supply chain, both upstream and downstream.

In a similar fashion, all the burdens and benefits of the policy are also passed on. To which agent they accrue depends only on the elasticities of supply and demand for goods and primary inputs, but not on the accounting system. Thus, theoretically, the same international distribution of income can be achieved irrespective of which of the four accounting systems (and corresponding policies) is chosen. This, however, requires that - e.g. if climate policy is negotiated by means of the allocation of GHG emission rights - country endowments are set accordingly; for example, countries can be endowed with production-based emission permits or a corresponding amount of extraction-based emission permits. Political feasibility may, however, require a different allocation: E.g. extraction-based permits might be distributed only to extracting countries if an extraction-based accounting principle is introduced, whereas under a production-based system permits might only go to countries hosting emitting industries. Thus, the choice of a particular accounting system may also have distributional implications.

\section{Evaluation for "real world" circumstances}

Reality is characterized neither by complete and fully competitive markets nor by the near-term possibility of implementing a climate policy that encompasses all GHG emissions globally and that results at least implicitly in a uniform $\mathrm{CO}_{2}$ e price across all GHGs and countries. In such a "secondbest" world, climate policies pursued by individual countries or "coalitions of the willing" are (globally) less environmental and cost-effective than in a "first-best" world. How much effectiveness is lost typically depends on the particular accounting system choice (and the associated policies). ${ }^{62}$

Countries can influence three core areas by their climate policy - their production, their consumption, and their extraction of fossil fuels. Each of these policy areas is reflected - and best covered in terms of direct impacts on emissions - by one of the accounting approaches. Note that it is debatable whether downstream emissions, as recorded in income-based emissions accounts, can be directly addressed by policy. But while production-based, consumption-based, and extractionbased accounts are ideally suited to reflecting the impacts of specific policies, none of the four accounting methods covers all emissions that a country can influence and that it therefore could address through its policies, i.e. they all have their policy "blind spots". Thus, some emission reduction potentials are likely to remain unexploited. In particular, (i) the production-based accounting principle neither reflects a country's discretion with respect to choice of import supplier (and the corresponding GHG intensity of imports) nor with respect to the emissions enabled by fossil 
fuels extracted and exported; (ii) the consumption-based principle fails to reflect a country's discretion regarding its own exports (and their carbon intensity) and the fuels extracted and exported; (iii) the extraction-based principle fails to reflect a countries' discretion concerning production and consumption; and (iv) the income-based principle captures emissions associated with how a country earns its income, but not those related to how the income is spent.

But these most obvious ones are not the only "blind spots". In countries where national climate policy is not synchronized with global policy, national activities and policies may impact global emission levels indirectly via "carbon leakage". ${ }^{63,49,64}$ Carbon leakage refers to a change in emissions in non-abating countries which is triggered by the introduction of a (stricter) climate policy in abating countries. To date, this has primarily been analyzed for production-based policies. ${ }^{65}$ In the respective literature the most important of these indirect and typically unintended impacts are referred to as "leakage channels" and include the following effects: (i) national production-based climate policy may trigger redirection of trade flows or relocation of industry to other countries and thus increase emissions there (relocation or competitiveness channel); (ii) climate policy may reduce global fossil fuel demand and consequently bring down world fuel prices leading to a rise in fossil fuel demand (and thus in emissions) in "uncapped" world regions (energy market channel); (iii) climate policy induces a redistribution of income, typically causing changes in global emissions (income channel); (iv) climate policy induces development of (clean) technologies with possible spillover to other countries (technology spillover channel). The leakage concept can also be generalized to apply to the other accounting principles. ${ }^{47,43}$ E.g. for extraction-based accounting and related policies, the relocation channel may be considered to refer to the relocation of production capacities in extraction to uncapped regions. Leakage typically lowers the environmental and cost-effectiveness of a policy.

In comparing the four accounting principles, we often find that leakage reduction via one channel is associated with a rise in leakage via some other channel. For example, relative to production-based accounting, the extraction-based approach and an associated policy followed by some, but not all extracting countries, does not redirect trade flows in intermediate and final goods or lead to relocation of industry producing these goods, but may cause a redirection of trade in fossil fuels and a relocation of extraction sites to extracting countries that are not part of the abating coalition. These countries may also experience an increase in resource rents, possibly triggering emission effects through the income channel.

The blind spots of production-based accounting (and production-based policy variants) have been extensively studied in the quantitative carbon leakage literature by means of multiregional computable general equilibrium models. For larger abating coalitions, the energy market channel is typically found to be the quantitatively most important leakage channel, whereas for smaller 
coalitions the competitiveness channel usually dominates. ${ }^{66}$ The literature on border carbon adjustment provides insights into the effects of consumption-based policy variants. These may involve less leakage through the competitiveness channel than production-based policies, but if introduced by simple, easy-to-administer forms of BCA, there appears to be only little difference between the two policy variants in terms of cost-effectiveness. ${ }^{67}$ Furthermore, the consumptionbased policies' distributional effects typically work to the disadvantage of developing and emerging economies. ${ }^{44}$ Little is known about the quantitative importance of blind spots under extraction-based and income-based accounting. As energy market leakage appears to be large under the current accounting system, the further study of accounting systems that directly address fossil fuel supply, such as those based on extraction-based accounting, may be warranted. ${ }^{68,2}$

It has been suggested that some of the four accounting systems described here be combined into a single indicator. ${ }^{7,11,12,9}$ Some such proposals intend to thereby affect abatement burden-sharing, e.g. between producers and consumers. ${ }^{9,10}$ However, as burdens are passed on to others, the specific shares used in combining accounting indicators are unlikely to directly inform us about how burdensharing is really affected. ${ }^{47}$ As the distribution of burdens depends on demand and supply elasticities, only a model-based analysis of the proposed combined indicators will reveal their impacts on burden-sharing. Another motivation for constructing combined indicators is to provide countries with an improved instrument - with fewer blind spots - to monitor their own policy. The recent proposal of Technology Adjusted Consumption Based Accounting ${ }^{69}$ is an improvement on consumption-based accounting since it addresses the blind spot of a country's exports. Unfortunately, it introduces other shortcomings. For example, as emissions are not uniformly weighted, even when applied in a "first-best" setting, policies based on this indicator clearly lead to inefficiencies; in a "second-best" setting its properties depend on the specifics of the situation studied.

We conclude that all accounting systems - including single indicator combinations of them - and related policies are characterized by blind spots and leakage effects. Notwithstanding this, there are still some general arguments which support the use of specific accounting systems. These are discussed below.

\section{Scope of emissions covered}

In contrast to the other accounting principles, extraction-based accounting - at least in the form proposed in the literature ${ }^{2}$ - does not cover all GHGs: only $\mathrm{CO}_{2}$, and not even all $\mathrm{CO}_{2}$ emissions are included - process-related $\mathrm{CO}_{2}$ emissions not linked to fossil fuels (such as $\mathrm{CO}_{2}$ emissions from the chemical process in cement production) are not covered. On the other hand, even those fuels that 
are not combusted immediately, but employed as material input (e.g. to produce plastics), may be wrongly counted as emissions contributors. Therefore, extraction-based accounts are not suitable for use as the sole GHG emission monitoring or target base.

\section{Achievable environmental stringency}

In a second-best world, both the level of environmental stringency achievable as well as the scope of emissions targeted in abatement are likely to differ across GHG accounting systems. Environmental stringency on a global level may be enhanced by adopting an accounting system that allocates a larger share of emissions - and thus emission reductions - to those countries that express a stronger willingness to abate. Judging by the pledges made under the current UNFCCC process, extracting countries appear, on average, to be less ambitious than many industrialized countries. ${ }^{70,71}$ This suggests that using a consumption-based or income-based accounting system as a target-base rather than an extraction-based one is likely to enable stronger actual reductions.

\section{Transaction cost}

As there are far fewer parties extracting fossil fuels than there are burning these fuels or consuming goods that have been produced using fossil energy, transaction costs associated with monitoring and policy implementation are likely to be lowest in extraction-based accounting. ${ }^{2}$ Production-based accounting has benefited from the institutional and practical experience that has been gained via its use by the UNFCCC. This may have lowered respective transaction costs. No such experience has been gained with respect to consumption-based accounting. In addition, proposals for its practical implementation $^{59}$ (even simple ones relying on benchmarks ${ }^{56,57,58}$ ) appear to involve implementation and monitoring costs exceeding those of production-based accounting.

\section{Data uncertainty}

The degree of uncertainty for production-based accounting has repeatedly been analyzed. . $2,73,74,75$ For country level fossil $\mathrm{CO}_{2}$ emissions estimates of the $95 \%$ confidence interval uncertainties range from $3-5 \%$ up to $50 \%$ or more for countries with poor statistical infrastructures. ${ }^{76}$ Global emissions shift towards the latter type of countries, revisions thus are often of global significance. ${ }^{77}$ Incomeand consumption-based accounts are typically based on the production-based accounting system and employ additional modelling assumptions, as e.g. sectoral carbon intensities in foreign trade. ${ }^{78}$ They thus suffer from both the uncertainties of production-based accounting and those stemming from their own assumptions, with indications that the former fraction of uncertainty is larger than the latter. ${ }^{79,80}$ 
In addition, for reasons of practicability, consumption-based and income-based approaches may employ sectoral averages rather than product-specific carbon data. Thus the actual content of carbon embodied in a specific product might hugely diverge from that registered in the accounting scheme, raising concerns in terms of procedural justice and transparency. Agreed upon international norms may help to overcome these concerns and ease trade-related product-oriented climate policies ${ }^{50}$, similar as the adoption of the GATT rules of origin did.

\section{Beyond production-based GHG accounting in practice}

We have compared consumption-, income-, and extraction-based accounting to the currently applied principle of production-based accounting. Apart from these four accounting methods, which involve only current emissions, methods including historic ${ }^{81}$ or future (committed) emissions ${ }^{82,83,84}$ as well as methods relating to different levels of actors (governments, corporations, individuals) ${ }^{85,86,87}$ or addressing national dependence ${ }^{88}$ are discussed. In principle, accounts for historic or committed emissions can be generated according to each of the four accounting methods introduced here, e.g. for consumption-based emissions. ${ }^{89}$ Often, the inclusion of historic emissions intends to rebalance the international distribution of abatement burdens. Our discussion however shows that thereby in a second-best world also the effectiveness of the associated policies may be altered. An in-depth discussion of these further accounting dimensions and their links to our analysis is, however, beyond the scope of this Perspective.

Regarding the four accounting principles (and related policies) considered here, our discussion has shown that in a second-best world we cannot expect one policy option to fare best in terms of effectiveness or justice under all circumstances; what is best depends on the situation at hand. The possibility of utilizing not just one, but all four accounts will open up new options for the monitoring of emissions and for policy design in individual countries, "coalitions of the willing," and the UNFCCC. In the following, we present four such options.

\section{Multiple monitoring bases}

If the international climate policy framework continues to rely on a single type of abatement target such as production-based emissions, the three other carbon accounts could still be employed as additional monitoring bases. This would provide countries with a more complete picture of the effects of their actions and policies. ${ }^{90}$ Such ex-post policy performance analysis would be advantageous in that it would help inform the debate on mitigation in international climate 
negotiations, ${ }^{91}$ and could thus facilitate the development of future policy options. "Better" monitoring may thus be seen as a first step on the way to "better" policies.

\section{Switching the internationally agreed target base}

Some early authors suggested a switch in UN GHG accounting and target-setting to a consumptionbased system. ${ }^{5}$ Also, the possible advantages of the adoption of extraction-based accounting ${ }^{2}$ and policies ${ }^{68}$ have been explored. In the short term, however, international agreement on a switch in the target base appears unlikely. Our discussion shows that while such a switch may improve policy performance in terms of some criteria, it also introduces further problems. In particular, using extraction-based accounts as a target and instrument base may reduce transaction costs; but as only $\mathrm{CO}_{2}$ and not even all $\mathrm{CO}_{2}$ emissions are covered, additional accounting schemes for other GHGs would need to be introduced; also, the level of policy stringency achievable might be low. On the other hand, to be cost-effective, a fully consumption-oriented target and instrument system requires information on embodied carbon established globally by bottom-up methods ${ }^{43}$ - which does not seem practicable at the moment - or alternatively, that mitigation projects in countries that are not part of the "coalition of the willing" are directly supported".

\section{Multiple instrument bases}

If the international target base remains production-based, in a second-best world countries willing to pursue an ambitious climate policy may nevertheless find that the optimal policy mix employs a combination of instruments based on different accounting systems to minimize leakage. For example, proposals for border carbon adjustments that include only imports, but not exports, ${ }^{57,58,59}$ combine a production-based with a consumption-based approach. Other combinations of accounting systems are conceivable, e.g. some countries might be willing to complement the current production-based instruments by employing depletion quotas, an extraction-based policy instrument.

\section{Parallel agreements based on different accounting systems}

The scope of emissions targeted in reduction may be enhanced on a global level not only by increasing the number of countries that commit themselves to targets under the current productionbased system, but also by complementing these commitments by ones based on an alternative accounting principle. This suggests that research on parallel climate agreements among disjunctive or partly overlapping groups of participating countries may be warranted. For example, if a group of countries coordinates to introduce BCA, this constitutes an agreement on consumption-based accounting in parallel to the UNFCCC's production-based system. As another example, envision a 
group of extracting countries that follow the example Ecuador's Yasuni ITT initiative and agree on a permanent confiscation of a fraction of in situ carbon resources ${ }^{93}$ accompanied by financial compensation. As shown for the current system, overlapping regulations may, however, also have adverse effects on policy effectiveness.$^{94}$ In addition, negotiations on multiple agreements may slow down progress on a globally coordinated and harmonized abatement strategy. Multi-agreement paths therefore need to be explored carefully before any conclusions are drawn regarding their practicability.

\section{The way ahead}

We argue that none of the above accounting systems - nor any type of combination - is per se "best" when attempting to generate a just and effective climate policy in a second-best world. The relative justice and effectiveness of each proposal depend on specifics such as the size and the composition of the abating coalition, the stringency of the targets envisioned, the responsiveness of demand and supply of goods and factors of production to price changes, market structures, trade flows, and technologies available. Furthermore, the creation of undesirable distributional effects is no reason to automatically reject a particular variant since the distribution of burdens can always be changed through side-payments or by rechanneling the revenues associated with the application of the climate policy instruments (e.g. carbon tax revenues). ${ }^{47}$ At any rate, only a detailed analysis of the situation at hand - possibly with the help of simulation models - will allow a ranking of the accounting systems. Today, lack of adequate data means that there are still limits to not only performing such comprehensive analyses, but also to introducing new policies linked to a transparent and thus internationally accepted data basis. We therefore suggest compiling consistent and reliable data as required for the calculation of consumption-based, income-based, and extraction-based GHG accounts, in an internationally agreed upon procedure, acknowledging data uncertainties, and possibly at shorter intervals than at present. This would facilitate the introduction of multiple monitoring bases as discussed above.

The availability of multiple GHG accounts is expected to result in several advantages:

- an improvement in transparency and knowledge concerning GHG transfers across economic sectors and countries

- a more complete and accurate picture for specific countries of the impact of their policies on global emissions

- support of a more informed debate on mitigation in international negotiations

- an improvement in ex-ante mapping of possible GHG mitigation pathways 
- benefits for the development of climate policy instruments due to an internationally agreed data basis and standard these can refer to

- a better basis for countries willing to tackle climate change by employing additional, more effective abatement policies

- possibly the facilitation of parallel agreements based on different accounting systems.

\section{Satellite accounts}

Recent developments in the system of national accounts can help point the way in establishing a system of multiple GHG accounting. In the 1990s the traditional System of National Accounting (SNA) depicting economic activities was expanded by satellite accounts (to reflect changes in natural and environmental resource stocks and flows). ${ }^{95,96,97}$ Similarly, in carbon accounting, the considerable experience gained in the provision of energy and process emission statistics, on which productionbased carbon accounting and its international monitoring rely, suggests that such accounts be retained as core indicator. However, we also propose inclusion of the three other GHG accounting schemes in the internationally established GHG accounting system, in the form of satellite accounts based on common guidelines. This would keep current emission balances intact, while at the same time improving our knowledge on GHG transfers throughout the supply chain and possibly opening up options for the implementation of more just and effective policies.

\section{Acknowledgements}

Research was supported by research grants of the Climate and Energy Fund within the Austrian Climate Research Programme (projects INNOVATE and RE-ADJUST). The authors thank Douglas Crawford-Brown, Gottfried Kirchengast, Andreas Richter and three anonymous reviewers of this journal for extremely helpful comments on earlier versions. Thanks to Sabine Tschuertz for her work on the figures.

\section{References:}

1. UNFCCC. The Kyoto Protocol to the Framework Convention on Climate Change (1997). Available at: http://unfccc.int/essential_background/kyoto_protocol/background/items/1351.php.

2. Davis, S.J., Peters, G.P. \& Caldeira, K. The supply chain of $\mathrm{CO}_{2}$ emissions. Proc. Natl. Acad. Sci. U.S.A. 108, 18554-18559 (2011).

3. Lenzen, M. \& Murray, J. Conceptualising environmental responsibility. Ecol. Econ. 70, 261-270 (2010).

4. Marques, A., Rodrigues, J., Lenzen, M. \& Domingos, T. Income-based environmental responsibility. Ecol. Econ. 84, 57-65 (2012).

5. Peters, G. \& Hertwich, E.G. Post-Kyoto greenhouse gas inventories: production versus consumption. Clim. Change 86 (1-2) 51-66 (2008). 
6. Davis, S.J. \& Caldeira, K. Consumption-based accounting of $\mathrm{CO}_{2}$ emissions. Proc. Natl. Acad. Sci. U.S.A. 107, 5687-5692 (2010).

7. Kondo, Y., Y. Moriguchi \& H. Shimizu. $\mathrm{CO}_{2}$ Emissions in Japan: Influences of Imports and Exports. Applied Energy 59 (2-3), 163-174 (1998).

8. Munksgaard, J. \& Pedersen, K. $\mathrm{CO}_{2}$ accounts for open economies: producer or consumer responsibility? Energy Policy 21, 327-334 (2001).

9. Ferng, J.-J. Allocating the responsibility of $\mathrm{CO}_{2}$ over-emissions from the perspectives of benefit principle and ecological deficit. Ecol. Econ. 46, 121-141 (2003).

10. Bastianoni, S., Pulselli, F.M. \& Tiezzi, E. The problem of assigning responsibility for greenhouse gas emissions. Ecol. Econ. 49, 253-257 (2004).

11. Lenzen, M., Murray, J., Sack, F. \& Wiedmann, T. Shared producer and consumer responsibility - Theory and practice. Ecol. Econ. 61, 27-42 (2007).

12. Rodrigues, J., Domingos, T., Giljum, S. \& Schneider, F. Designing an indicator of environmental responsibility. Ecol. Econ. 59, 256-266 (2006).

13. Feinberg, J. Harm to Others (The Moral Limits of the Criminal Law) (Oxford University Press, USA, 1984). ISBN: 0195034090.

14. Coleman, J. L. Risks and Wrongs: Philosophical Analysis (Cambridge University Press Archive, 1992). ISBN: 9780521428613.

15. McKinnon, C. Climate Change and Future Justice: Precaution, Compensation and Triage (Routledge, 2011). ISBN: 0415461251.

16. Gosseries, A. Historical emissions and free riding. Ethical Perspectives 11, $36-60$ (2004).

17. Caney, S. Environmental degradation, reparations, and the moral significance of history. Journal of Social Philosophy 37, 464 - 482 (2006). doi: 10.1111 / j.1467- 9833.2006.00348.x, ISSN: 0047-2786, 1467 - 9833.

18. Meyer L. H., \& Roser, D. Climate justice and historical emissions. Critical Review of International Social and Political Philosophy 13, 229 - 253 (2010). doi: 10.1080 / 13698230903326349, ISSN: 1369-8230.

19. Meyer, L. H. Why Historical Emissions Should Count. Chicago Journal of International Law 13, $597-685$ (2013).

20. De-Shalit, A. Why Posterity Matters: Environmental Policies and Future Generations. (Routledge, 1995) ISBN: 9780415100182

21. Thompson, J. Historical Injustice and Reparation: Justifying Claims of Descendants. Ethics 112, $114-135$ (2001). doi: 10.1086 / 339139, ISSN: 0014-1704, 1539-297X.

22. Thompson, J. Intergenerational Justice: Rights and Responsibilities in an Intergenerational Polity (Taylor \& Francis, US, 2009). ISBN: 978 - 0415996280.

23. Miller, D. Holding nations responsible. Ethics 114, 240 - 268 (2004). doi: 10.1086 / 379353, ISSN: 00141704, $1539-297 X$.

24. Butt, D. On benefiting from injustice. Canadian Journal of Philosophy 37, 129 - 152 (2007). doi: 10.1353 / cjp.2007.0010, ISSN: 1911-0820.

25. Parfit, D. Reasons and Persons Ch. 2 (Clarendon Press, Oxford, 1984).

26. Sinnott-Armstrong, W. It's not my fault: Global warming and individual moral obligations. Perspectives on Climate Change: Science, Economics, Politics, Ethics. Advances in the Economics of Environmental Research 5, 293-315 (2005).

27. Kagan, S. Do I make a Difference? Philosophy \& Public Affairs 39, 105-141 (2011).

28. Sandberg, J. My emissions make no difference. Environmental Ethics 33, 229-248 (2011).

29. Nefsky, J. Consequentialism and the Problem of Collective Harm: A Reply to Kagan. Philosophy \& Public Affairs 39, 364-395 (2012).

30. Maltais, A. Radically non-ideal Climate Politics and the Obligation to at least Vote Green. Environmental Values 22(5), 589-608 (2013).

31. May, L. \& Hoffman, S. (eds.). Collective Responsibility: Five Decades of Debate in Theoretical and Applied Ethics (Rowman \& Littlefield, 1991).

32. Mellema, G. Collective responsibility and contributing to an outcome, Criminal Justice Ethics 25(2), 17-22 (2006).

33. Parfit, D. Reasons and Persons Ch. 16 (Clarendon Press, Oxford, 1984).

34. Heyd, D. Genethics: Moral Issues in the Creation of People (Univ. of. California Press, Berkeley, 1992).

35. Birnbacher, D. What motivates us to care for the (distant) future? In: Gosseries, A. \& Meyer, L. H. (eds.) Intergenerational Justice, 273-300 (Oxford University Press, Oxford, 2009). 
36. Gardiner, S. M. A Perfect Moral Storm: The Ethical Tragedy of Climate Change (Oxford University Press, USA, 2011). ISBN: 0195379446.

37. Meyer, L. H. \& Sanklecha, P. Individual Expectations and Climate Change. Analyse \& Kritik: Zeitschrift fuer Sozialtheorie 32, $449-471$ (2011).

38. Meyer, L. H. \&Sanklecha, P. How Legitimate Expecations Matter in Climate Justice. Politics, Philosophy \& Economics 13, 369 - 393 (2014).

39. Jamieson, D. Global Responsibilities: Ethics, Public Health, and Global Environmental Change. Indiana Journal of Global Legal Studies 5, 99 - 119 (1997).

40. Shue, H. Global environment and international inequality. International Affairs 75, 531 - 545 (1999). doi: 10.1111 / 1468 - 2346.00092, ISSN: 0020-5850, 1468 - 2346.

41. Caney, S. Climate change and the duties of the advantaged. Critical Review of International Social and Political Philosophy 13, 203 - 228 (2010). doi: 10.1080 / 13698230903326331, ISSN: 1369-8230, 1743 8772.

42. Whalley, J. \& Wigle, R. The international incidence of carbon taxes. In: Dornbusch, R. \& Poterba, J. (eds). Economic Policy Responses to Global Warming (MIT Press, Cambridge, MA, 1991)

43. Lininger, C. Consumption-Based Approaches in International Climate Policy (Springer, Cham, 2015).

44. Böhringer, C., Balistreri, E. \& Rutherford, T. The role of border carbon adjustment in unilateral climate policy: overview of an Energy Modeling Forum study (EMF29). Energy Econ. 34 (Suppl. 2), S97-S110 (2012).

45. Mattoo, A., Subramanian, A., van der Mensbrugghe, D. \& He, J. Reconciling Climate Change and Trade Policy. World Bank Policy Research Working Paper No. 5123. World Bank, Washington D.C. (2009).

46. Kolstad C. et al. Social, Economic and Ethical Concepts and Methods. In: Edenhofer, O. et al. (eds.). Climate Change 2014: Mitigation of Climate Change. Contribution of Working Group III to the Fifth Assessment Report of the Intergovernmental Panel on Climate Change. (Cambridge University Press, Cambridge, UK and New York, NY, USA, 2014).

47. Steininger, K.W., Lininger, C., Droege, S., Roser, D., Tomlinson, L. \& Meyer, L. Justice and cost effectiveness of consumption-based versus production-based approaches in the case of unilateral climate policies, Global Environmental Change 24, 75-87 (2014).

48. Peters,G.P. \& Hertwich, E.G. Post-Kyoto greenhouse gas inventories: Production versus consumption. Climatic Change 86(1-2), 51-66 (2008).

49. Droege, S. et al. Tackling leakage in a world of unequal carbon prices. Report. Climate Strategies, Cambridge (2009).

50. Girod, B. Product-oriented climate policy: Learning from past evolution for its potential future development. J. of Cleaner Prod (forthcoming).

51. Babiker, M.H. \& Rutherford, T.F. The economic effects of border measures in subglobal climate agreements. Energy Journal 26(4), 99-126 (2005).

52. Kuik, O., \& Hofkes, M. Border adjustment for European emissions trading: competitiveness and carbon leakage. Energy Policy 38(4): 1741-1748 (2010).

53. Fischer, C. \& Fox, A.K. Comparing Policies to Combat Emissions Leakage: Border Carbon Adjustments versus Rebates. Journal of Environmental Economics and Management 64 (2), 199-216 (2012).

54. Bednar-Friedl, B., Schinko, T. \& Steininger, K.W. The relevance of process emissions for carbon leakage: A comparison of unilateral climate policy options with and without border carbon adjustment. Energy Economics 34 (Suppl 2), S168-S180 (2012).

55. Antimiani, A., Costantini, V., Martini, C., Salvatici, L. \& Tommasino, M.C. Assessing alternative solutions to carbon leakage. Energy Economics 36, 299-311 (2013).

56. Ismer, R. \& Neuhoff, K. Border tax adjustment: a feasible way to support stringent emission trading. European Journal of Law and Economics 24, 137-164 (2007).

57. Monjon, S. \& Quirion, P. How to design a border adjustment for the European Union emissions trading system? Energy Policy 98(9), 5199-5207 (2010).

58. Cosbey, A. et al. A Guide for the Concerned: Guidance on the elaboration and implementation of border carbon adjustment. Policy report 03 (November). Entwined, Stockholm. Available at: <http://www.iisd.org/pdf/2012/bca_guidance.pdf> (2012).

59. Gros, D., Egenhofer, C., Fujiwara, N., Georgiev, A. \& Guerin, S.S. Climate Change and Trade: Taxing carbon at the border? CEPS Paperbacks. Center for European Policy Studies, Brussels (2010).

60. European Parliament and the Council of the EU. Directive 2009/29/EC of the European Parliament and of the Council of 23 April 2009 amending Directive 2003/87/EC so as to improve and extend the greenhouse 
gas emission allowance trading scheme of the Community. Official Journal of the European Union, L 140, 5 June 2009: 63-86.

61. Harstad, B. Buy Coal! A Case for Supply-Side Environmental Policy. Journal of Political Economy 120 (1), $77-$ 115 (2012).

62. Markusen, J. R. International externalities and optimal tax stuctures, Journal of International Economics 5, 15-29 (1975).

63. Felder, S. \& Rutherford, T.F. Unilateral Action and Carbon Leakage: The Consequences of International Trade in Oil and Basic Materials. Journal of Environmental Economics and Management 25, 162-176 (1993).

64. Quirion, P. Competitiveness and Leakage. In: Cerda, E. \& Labandeira, X. (eds.), Climate Change Policies: Global Challenges and Future Prospects (Edward Elgar Publishing, Cheltenham, 2010).

65. Kanemoto, K., Moran, D., Lenzen, M. \& Geschke, A. International trade undermines national emission reduction targets: New evidence from air pollution. Global Environmental Change 24, 52-59 (2014).

66. Burniaux, J.-M. \& Oliveira Martins, J. Carbon leakages: a general equilibrium view. Economic Theory 49, 473-495 (2012).

67. Boehringer, C., Bye, B., Faehn, T., Rosendahl, K.E. Alternative designs for tariffs on embodied carbon: A global cost-effectiveness analysis. Energy Econ. 34, 143-153 (2012).

68. Whalley, J. \& Wigle, R., Cutting $\mathrm{CO}_{2}$ emissions: The effects of alternative policy approaches. The Energy Journal 12, 109-124 (1991).

69. Kander, A., Jiborn, M., Moran, D.D. \& Wiedmann, T.O., National greenhouse-gas accounting for effective climate policy on international trade. Nature Climate Change 5, 431-435 (2015), doi:10.1038/nclimate2555

70. UNFCCC. Compilation of economy-wide emission reduction targets to be implemented by Parties included in Annex I to the Convention. FCCC/SBSTA/2014/INF.6. (United Nations Framework Convention on Climate Change, Bonn, 2014).

71. UNFCCC. Compilation of information on nationally appropriate mitigation actions to be implemented by developing country Parties. FCCC/SBI/2013/INF.12/Rev.3. (United Nations Framework Convention on Climate Change, Bonn, 2013).

72. Lieberman, D. et al. (eds). Accounting for climate change. Uncertainty in Greenhouse Gas Inventories Verification, Compliance, and Trading (Springer, Dordrecht, 2007).

73. White, T. et al. (eds). Greenhouse Gas Inventories: Dealing With Uncertainty (Springer, Dordrecht, 2011).

74 Ometto, J.P., Bun, R., Jonas, M. \& Nahorski, Z. Uncertainties in Greenhouse Gas Emission Inventories (Springer, Cham, 2015).

75. Bellassen, V. et al. Monitoring, reporting and verifying emissions in the climate economy, Nature Climate Change 5, 319-328 (2015).

76. Andres, R. J. et al. A synthesis of carbon dioxide emissions from fossil-fuel combustion. Biogeosciences 9 , 1845-1871 (2012).

77. Liu, Z. et al. Reduced carbon emission estimates from fossil fuel combustion and cement production in China. Nature 524, 335-338 (2015).

78. Wilting, H.C. Sensitivity and uncertainty analysis in MRIO modelling; some empirical results with regard to the Dutch carbon footprint. Economic Systems Research 24(2), 141-171 (2012).

79. Inomata, S. \& Owen, A. (eds.). A Comparative Evaluation of Multi-Regional Input-Output Databases, Special Issue, Economic Systems Research 26 (3) (2014).

80. Peters, G. P., Davis, S. J. \& Andrew, R. A synthesis of carbon in international trade. Biogeosciences 9, 39494023 (2012).

81. Matthews, H.D. et al. National contributions to observed global warming. Environmental Research Letters 9 , 014010 (2014).

82. Davis, S.J. \& Socolow, R.H. Commitment accounting of $\mathrm{CO}_{2}$ emissions. Environmental Research Letters $\mathbf{9}$, 084018 (2014).

83. Davis, S. J., Caldeira, K. \& Matthews, H. D. Future $\mathrm{CO}_{2}$ Emissions and Climate Change from Existing Energy Infrastructure. Science 329, 1330-1333 (2010).

84. Raupach, M.R. et al. Sharing a quota on cumulative carbon emissions. Nature Climate Change 4, 873-879 (2014).

85. Skelton, A. EU corporate action as a driver for global emissions abatement: A structural analysis of EU international supply chain carbon dioxide emissions. Global Environmental Change 23, 1795-1806 (2013).

86. Heede, R. Tracing anthropogenic carbon dioxide and methane emissions to fossil fuel and cement producers, 1854-2010. Climatic Change 122, 229-241 (2014). 
87. Chakravarty, S. et al. Sharing global $\mathrm{CO}_{2}$ emission reductions among one billion high emitters. Proc. Natl. Acad. Sci. U.S.A. 106, 11884-11888 (2009).

88. Andrew, R., Davis, S. J. \& Peters, G. P. Climate policy and dependence on traded carbon. Environmental Research Letters 8, 034011 (2013).

89. Matthews, H.D. Quantifying historical carbon and climate debts among nations. Nature Climate Change, DOI: 10.1038/NCLIMATE2774.

90. Peters, G. Managing carbon leakage. Carbon Management 1, 35-37 (2010).

91. Edenhofer, O. \& Minx, J., Mapmakers and navigators, facts and values. Science 354(6192), 37-38 (2014).

92. Springmann, M. Carbon tariffs for financing clean development. Climate Policy 13(1), 20-42 (2013).

93. Asheim, G.B. A Distributional Argument for Supply-Side Climate Policies. Environ Resource Econ 56,239-254 (2013).

94. Böhringer, C. \& Behrens, M. Interactions of Emission Caps and Renewable Electricity Support Schemes, J Regul Econ 48,74-96 (2015)

95. Bartelmus, P., Stahmer, C. \& van Tongeren, J. Integrated Environmental and Economic Accounting: Framework for a SNA Satellite System, Review of Income and Wealth 37, 111-148 (1991).

96. United Nations Statistics Division, Integrated Environmental and Economic Accounting, Studies in Methods, No. 61, (United Nations, New York, Publication E.93.XVII.12, 1993).

97. United Nations, Handbook of National Accounting: Integrated Environmental and Economic Accounting - An Operational Manual (United Nations, New York, Studies in Methods Series F, No. 78, 2000). 